"This is the peer reviewed version of the following article: [J. Am. Chem. Soc. 2016, 138, 6, 17841787] which has been published in final form at [Link to final article using the DOI: doi.org/10.1021/jacs.5b12620]. This article may be used for non-commercial purposes in accordance with the American Chemical Society Terms and Conditions for Self-Archiving."

\title{
Synthesis and Structure of Nitride-Bridged Uranium(III) Complexes
}

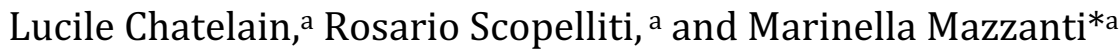 \\ ${ }^{a}$ Institut des Sciences et Ingénierie Chimiques, Ecole Polytechnique Fédérale de Lausanne (EPFL), CH-1015 Lausanne, \\ Switzerland.
}

Supporting Information Placeholder

ABSTRACT: The reduction of the nitride bridged diuranium(IV) complex $\mathrm{Cs}\left[\left\{\mathrm{U}\left(\mathrm{OSi}\left(\mathrm{O}^{\mathrm{t}} \mathrm{Bu}\right)_{3}\right)_{3}\right\}_{2}(\mu-\mathrm{N})\right]$ affords the first example of a uranium nitride complex containing uranium in the +III oxidation state. Two nitride bridged complexes containing the heterometallic fragments $\mathrm{Cs}_{2}\left[\mathrm{U}^{\mathrm{III}} \mathrm{H}_{--} \mathrm{N}=-\mathrm{U}^{\mathrm{IV}}\right]$, and $\mathrm{Cs}_{3}\left[\mathrm{U}^{\mathrm{III}}=-\mathrm{N}_{---} \mathrm{U}^{\mathrm{III}}\right]$ have been crystallographically characterized. The presence of two or three $\mathrm{Cs}^{+}$cations binding the nitride group is key for the isolation of these complexes. In spite of the fact that the nitride group is multiply bound to two uranium and two or three $\mathrm{Cs}^{+}$cations, these complexes transfer the nitride group to $\mathrm{CS}_{2}$ to afford SCN- and uranium(IV) disulfide.

Molecular uranium nitrides are attractive synthetic targets due to their potential as precursor to ceramic materials or as efficient molecular catalysts.[1] Notably, uranium(III) mononitride, $\mathrm{UN}^{[2]}$ a solid that is difficult to synthetize and to solubilize, has been proposed for alternative nuclear fuels ${ }^{[3]}$ and as an effective catalyst in dinitrogen reduction to ammonia.[4]
Moreover, molecular nitride complexes are also important to gain a better understanding of $f$ orbital implication in multiple bonding and covalency in actinide-ligand bonds. [5] Uranium nitride chemistry remains much less developed than the d-block counterparts. In recent years several molecular complexes of uranium have been prepared that contain nitride groups bridging two or more uranium ions, ${ }^{[6]}$ or terminal nitride groups. ${ }^{[7]}$ Most of these complexes contain uranium in its oxidation state $+\mathrm{IV}$, with a few systems containing $\mathrm{U}(\mathrm{V})$ and $\mathrm{U}(\mathrm{VI})$. In spite of their relevance in materials science and catalysis, and of the anticipated attractive reactivity of U(III) nitrides, no molecular uranium(III) nitride complex has been isolated in solution or in the solid state. The isolation of molecular U(III) nitrides is essential to investigate the reactivity of the UIII-nitride bond which in turn will lead to convenient routes to nitride materials and to the design of molecular catalysts.

Here we report the first examples of nitride-bridged complexes containing uranium in the oxidation state + III. 
Recently we had reported the synthesis and the molecular structure of the dinuclear uranium(IV)/uranium(IV) nitride $\mathrm{Cs}\left[\left\{\mathrm{U}\left(\mathrm{OSi}\left(\mathrm{O}^{\mathrm{t}} \mathrm{Bu}\right)_{3}\right)_{3}\right\}_{2}(\mu-\mathrm{N})\right], \mathbf{1}$. This complex remains a rare example ${ }^{[6 f, 6 \mathrm{~h}]}$ of a dinuclear uranium nitride complex featuring a linear $\mathrm{U}^{\mathrm{IV}}-\mathrm{-N}_{---} \mathrm{U}^{\mathrm{IV}}$ fragment (U-N-U angle : $\left.170.2(3)^{\circ}\right)$ and short U-N distances (U1-N1 2.058(5) Å, U2-N1 2.079(5) Å) indicative of a multiple $\mathrm{U}-\mathrm{N}$ bond. Moreover, in complex 1 the $\mathrm{Cs}^{+}$cation binds the bridging nitride and six oxygen atoms from the siloxide ligands affording a unique heterometallic structure. The ability of the ligand $\mathrm{OSi}\left(\mathrm{O}^{\mathrm{t}} \mathrm{Bu}\right)_{3}$ to bind to $\mathrm{Cs}^{+}$, thus stabilizing highly charged species, motivated us to explore the possibility of stabilizing the $\mathrm{U}_{---\mathrm{N}=-\mathrm{U}}$ fragment in highly reduced uranium species.

The reduction of complex 1 with 1 equivalent or a large excess of $\mathrm{Cs}^{0}$ in THF at $-40^{\circ} \mathrm{C}$ and under argon allowed the synthesis and the characterization of the $\mathrm{U}(\mathrm{III}) / \mathrm{U}(\mathrm{IV})$ complex $\mathrm{Cs}_{2}\left[\left\{\mathrm{U}\left(\mathrm{OSi}\left(\mathrm{O}^{\mathrm{t}} \mathrm{Bu}\right)_{3}\right)_{3}\right\}_{2}(\mu-\mathrm{N})\right], 2$ in $67 \%$ yield and the U(III)/U(III) complex $\mathrm{Cs}_{3}\left[\left\{\mathrm{U}\left(\mathrm{OSi}\left(\mathrm{O}^{\mathrm{t}} \mathrm{Bu}\right)_{3}\right)_{3}\right\}_{2}(\mu-\mathrm{N})\right], 3$ in $77 \%$ yield, respectively (Scheme 1). The solid state molecular structure of complexes $\mathbf{2}$ and $\mathbf{3}$ were determined by single-crystal X-ray diffraction (Figure 1 and Figure 2).

In both complexes $\mathbf{2}$ and $\mathbf{3}$, each uranium ion is coordinated by a nitride group and three siloxide oxygens with a pseudo-tetrahedral geometry. The two U$\mathrm{N}$ distances in complex $\mathbf{3}$ are equivalent as a result of the two-fold crystallographic axis passing through one Cs and the nitride ion. In complex 2 the two U-N distances (Table 1) are similar suggesting the presence of non-localized charge.

\section{Scheme 1. Synthesis of $\mathrm{Cs}_{2}\left[\left\{\mathrm{U}\left(\mathrm{OSi}\left(\mathrm{O}^{\mathrm{t} B u}\right)_{3}\right)_{3}\right\}_{2}(\mu-\right.$} $\mathrm{N})], 2$ and $\mathrm{Cs}_{3}\left[\left\{\mathrm{U}\left(\mathrm{OSi}\left(\mathrm{O}^{\mathrm{t}} \mathrm{Bu}\right)_{3}\right)_{3}\right\}_{2}(\mu-\mathrm{N})\right], 3$.

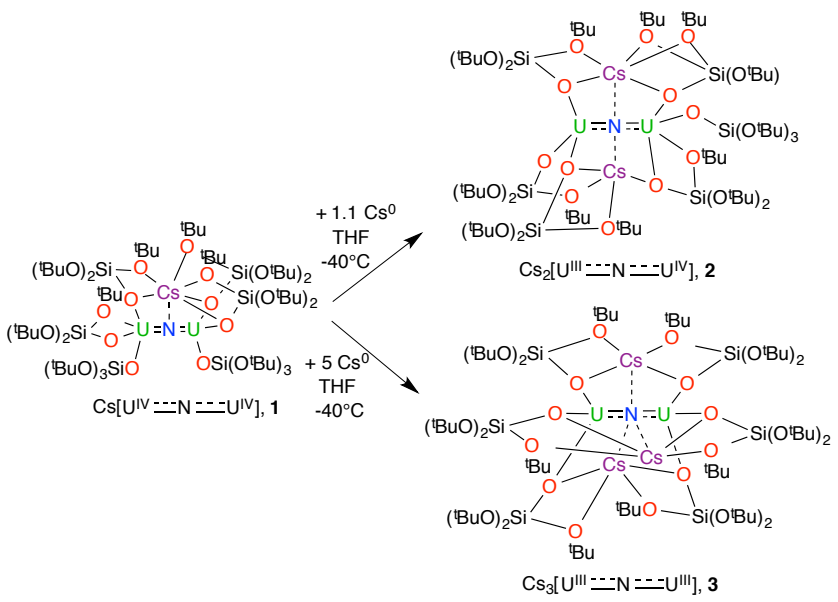

In all complexes 1-3 the $\mathrm{Cs}^{+}$cations are bound to the bridging nitride and to the siloxide oxygens. In complex 2 two $\mathrm{Cs}^{+}$cations bind the nitride in an almost linear way (Cs-N-Cs angle $\left.=161,8(4)^{\circ}\right)$ with the Cs-N-Cs and the $\mathrm{U}=-\mathrm{N}=-\mathrm{U}$ fragments located in the same plane and perpendicular to each other. In $\mathbf{3}$ three $\mathrm{Cs}^{+}$cations bind the nitride forming an irregular triangle located in a plane perpendicular to the $\mathrm{U}_{---} \mathrm{N}--\mathrm{U}$ fragment (Cs-N-Cs angles: 119.1(4). 108.9(3) and 132.0(7) ${ }^{\circ}$ ). The Cs- $\mathrm{N}$ distances are longer than those found in a U(IV) imido bridged complex (mean Cs- $\mathrm{N}=3.075(10)$ $\AA$ ).[7d]

Table 1. Comparative structural parameters of complexes 1-3

\begin{tabular}{|c|c|c|c|}
\hline & $\begin{array}{c}{\left[U^{I V}=--N=-U^{I V}\right]} \\
1\end{array}$ & $\begin{array}{c}{\left[U^{\prime \prime \prime}=-\mathrm{N}=--U^{\prime V}\right]} \\
2\end{array}$ & $\begin{array}{c}{\left[\mathrm{U}^{\prime \prime \prime}=-\mathrm{N}=-\mathrm{U}^{\prime \prime \prime}\right]} \\
3\end{array}$ \\
\hline U1-N (Å) & $2.058(5)$ & $2.099(12)$ & \multirow{2}{*}{$2.1495(12)$} \\
\hline U2-N (Å) & $2.079(5)$ & $2.081(12)$ & \\
\hline U-O avg $(\AA ̊)$ & $2.19(3)$ & $2.243(25)$ & $2.282(24)$ \\
\hline Cs1-N (Å) & \multirow{2}{*}{$3.393(4)$} & $3.276(12)$ & $3.348(8)$ \\
\hline Cs2-N (Å) & & $3.635(12)$ & $3.22(2)$ \\
\hline $\mathrm{U}-\mathrm{N}-\mathrm{U}\left({ }^{\circ}\right)$ & $170.2(3)$ & 169.1(7) & $174.2(11)$ \\
\hline
\end{tabular}

Complexes $\mathbf{2}$ and $\mathbf{3}$ display a linear $\mathrm{U}--\mathrm{N}-\mathrm{N}-\mathrm{U}$ motif with $\mathrm{U}-\mathrm{N}-\mathrm{U}$ angles comparable to those found in complex 1 (Table 1). The U-N distances for complexes 2 and 3 fall in the range 2.081-2.1495 $\AA$ and they are longer than those found in $\mathbf{1}^{[\mathrm{gg}]}$ and in the previously reported $U(I V) / U(V)$ nitrides containing the linear $\mathrm{U}=\mathrm{N}=\mathrm{U}$ motif (ranging from 2.012(16)-2.090(8) Å). ${ }^{6 \mathrm{Ga}}$ 6f, 6h] These distances remain much shorter than $\mathrm{U}(\mathrm{III})-\mathrm{N}$ single bond distances (for example: $\mathrm{U}-\mathrm{N}_{\text {cyanate }}$ $=2.456(7) \AA,[8] U-N_{\text {dinitrogen }}=2.401(8)-2.423(8) \AA{ }^{[9]}$ or $\mathrm{U}-\mathrm{N}_{\text {amide }}=2.320(4) \AA ̊$ in U[N(SiMe3)2]3 [10]). Longer U$\mathrm{N}$ distances were also found in a U(IV) cluster with a $\mathrm{U}_{4}\left(\mu_{4}-\mathrm{N}\right)$ core $(2.271(3)-2.399(5) \AA) .[6 \mathrm{~d}]$ This points to the presence of UIII-N multiple bonding in $\mathbf{2}$ and $\mathbf{3}$. The mean value of the U-N bond distance in the nitride core increases by about $0.08 \AA$ in the fully reduced $\mathrm{Cs}_{3}\left[\mathrm{U}^{\mathrm{III}}=-\mathrm{N}_{\left.---\mathrm{U}^{\mathrm{III}}\right]}\right.$ system as compared to the $\mathrm{Cs}\left[\mathrm{U}^{\mathrm{IV}} \underline{-.-}\right.$ $\left.\mathrm{N}=-\mathrm{U}^{\mathrm{IV}}\right]$ unit, probably due to the presence of additional electrons at the uranium center. Such an increase is similar to the increase in the average $\mathrm{U}-\mathrm{O}$ bond length $(0.09 \AA)$ that can be related to the difference in ionic radii between U(III) and U(IV) (0.135 $\AA$ ). A smaller variation $(0.03 \AA)$ was observed by Cummins and coworkers in the successive oxidation of a linear $\mathrm{U}(\mathrm{IV})=\mathrm{N}=\mathrm{U}(\mathrm{IV})$ fragment supported by amide ligands to $\mathrm{U}(\mathrm{V})=\mathrm{N}=\mathrm{U}(\mathrm{V}) .[6 \mathrm{ff}]$ The larger variation observed in the successive reduction of the siloxide complex $\mathbf{1}$ is, at least partly, due to the presence of an increasing number of $\mathrm{Cs}^{+}$cations binding the nitride group and thus polarizing and reducing the electron density on the $\mathrm{U}_{---} \mathrm{N}---\mathrm{U}$ fragment. The lengthening of $\mathrm{U}-\mathrm{N}$ bonding upon alkali ion coordination to the $\mathrm{N}$ has been observed in dinuclear U(IV) imido complexes.[7d] 


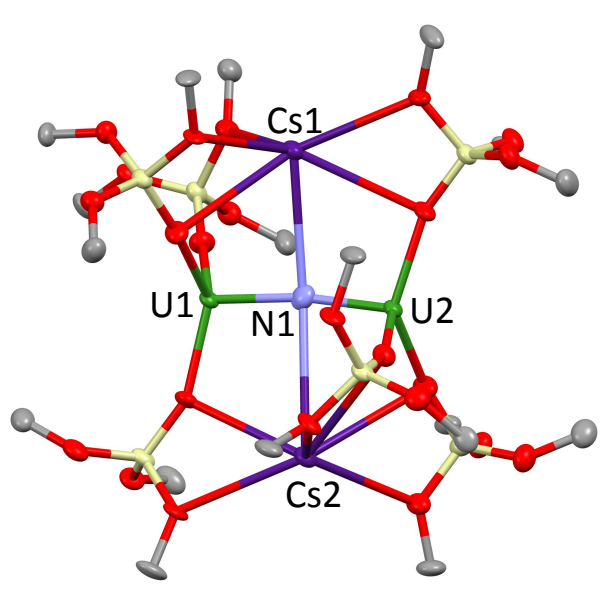

Figure 1. Crystallographic structure of $\mathrm{Cs}_{2}\left[\left\{\mathrm{U}\left(\mathrm{OSi}\left(\mathrm{O}^{\mathrm{t} B u}\right)_{3}\right)_{3}\right\}_{2}(\mu-\mathrm{N})\right], 2$ crystallized from a saturated THF solution; ellipsoid probability $50 \%$, with hydrogen atoms, methyl groups and solvent molecules omitted for clarity. Atoms: C (grey), 0 (red), Si (light yellow), N (light blue), Cs (purple) and U (green).

Complex 2 can be prepared analytically pure and stored in the solid state under argon at $-40{ }^{\circ} \mathrm{C}$ for several weeks, but is very reactive and can only be handled in solution at $-40{ }^{\circ} \mathrm{C}$. Complex 3 can be obtained analytically pure, but decomposes very quickly both in the solid state and in THF solution at $-40^{\circ} \mathrm{C}$ yielding mixtures of complexes $\mathbf{2}$ and $\mathbf{3}$ and free siloxide ligand. The extremely high reactivity of complexes $\mathbf{2}$ and $\mathbf{3}$ is in agreement with the absence in the literature of any molecular nitride compounds containing uranium in the oxidation state +III. The presence of the multidentate siloxide groups capable of binding the $\mathrm{Cs}^{+}$cation is key to the isolation of complex $\mathbf{3}$. Notably the reduction of 1 with an excess of $\mathrm{Cs}^{0}$ in the presence of crown ether 18C6 leads to intractable reaction mixtures containing the free ligand as the only NMR detectable species. This indicates that when the $\mathrm{Cs}^{+}$cation is removed by the crown ether from the coordination pocket formed by the siloxide ligands in $\mathbf{1}$, it becomes

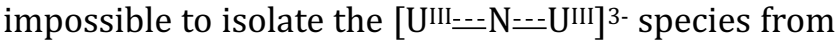
the reduction of 1 . The proton NMR spectra of complexes $\mathbf{2}$ and $\mathbf{3}$ in THF solution show the presence of only one signal for the six siloxide ligands in agreement with the presence of symmetry related siloxides. In the case of complex $\mathbf{2}$ this can interpreted in term of the fluxionality of the bound Cs cation. Proton NMR studies show that the addition of crown ether to complex 2 in THF results in the removal of the bound $\mathrm{Cs}^{+}$leading to a significant decrease of the stability. In contrast the addition of crown ether to complex 3 in THF does not lead to Cs removal.

Significant changes are also observed in the cyclic voltammogram of $\mathbf{1}$ when the electrochemistry is carried in the presence of 18C6. The cyclic voltammogram of complex 1 measured in THF (see sup. info.) shows two irreversible electrochemical events at -2.34 and $-0.92 \mathrm{~V}$ (vs $\left[\mathrm{Cp}_{2} \mathrm{Fe}\right]^{0 /+}$ ) corresponding to the reduction and the oxidation of the complex. The irreversibility of these redox events is probably due to the important rearrangement of the coordination sphere during the redox processes. After removal of $\mathrm{Cs}^{+}$the reduction wave is shifted at lower potential $\left(\mathrm{E}_{\mathrm{pc}}=-2.43 \mathrm{~V}\right)$ indicating that the reduction of complex $\mathbf{1}$ is more difficult in the absence of coordinated $\mathrm{Cs}^{+}$.

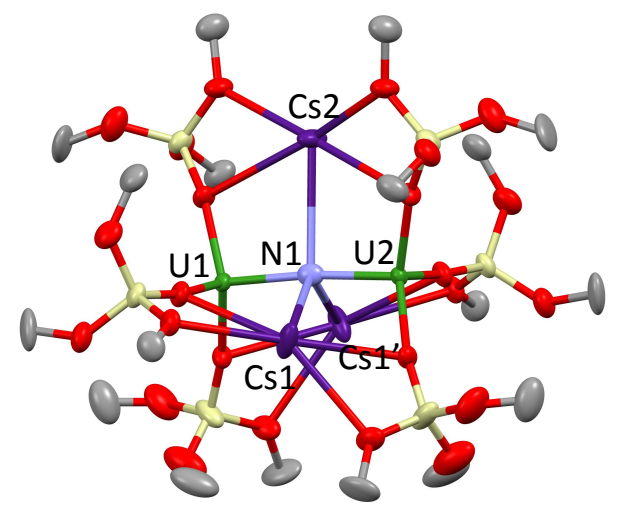

Figure 2. Crystallographic structure of $\mathrm{Cs}_{3}\left[\left\{\mathrm{U}\left(\mathrm{OSi}\left(\mathrm{O}^{\mathrm{t} B u}\right)_{3}\right)_{3}\right\}_{2}(\mu-\mathrm{N})\right], 3$ crystallized from a saturated THF solution; ellipsoid probability $50 \%$, with hydrogen atoms, methyl groups and disorder on Cs2 omitted for clarity. Atoms: C (grey), 0 (red), Si (light yellow), N (light blue), Cs (purple) and U (green).

Scheme 2. Reactivity of $\mathrm{Cs}_{2}\left[\left\{\mathrm{U}\left(\mathrm{OSi}\left(\mathrm{O}^{\mathrm{t} B u}\right)_{3}\right)_{3}\right\}_{2}(\mu-\right.$ $\mathrm{N})], 2$ and $\mathrm{Cs}_{3}\left[\left\{\mathrm{U}\left(\mathrm{OSi}\left(\mathrm{O}^{\mathrm{t}} \mathrm{Bu}\right)_{3}\right)_{3}\right\}_{2}(\mu-\mathrm{N})\right], 3$ with $\mathrm{CS}_{2}$.

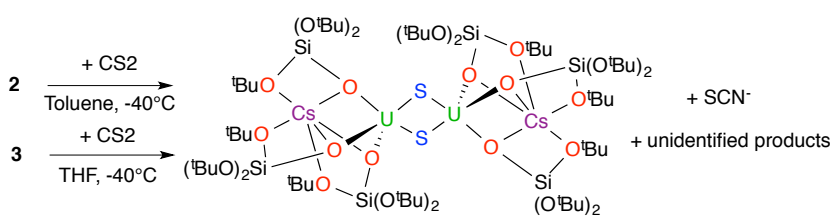

Complexes $\mathbf{2}$ and $\mathbf{3}$ provide the first examples of isolated molecular nitride complexes containing uranium in the oxidation state (III). These systems are expected to show high reactivity with a wide range of substrates due to the low oxidation state of uranium.[11] Previous reactivity studies of nitride-bridged uranium compounds are limited to a single example where the $\mathrm{U}^{\mathrm{IV}}=\mathrm{N}=\mathrm{U}^{\mathrm{IV}}$ fragment reacts as a masked metallonitrene with $\mathrm{NaCN} .[6 \mathrm{f}]$

Preliminary reactivity studies carried out with $\mathrm{CS}_{2}$ show that complexes $\mathbf{2}$ and $\mathbf{3}$ can transfer the nitride group to electrophilic substrates in spite of the fact that the nitride group is located in a protective pocket provided by the siloxide ligands and the multimetallic binding by two $\mathrm{U}$ and three Cs cations (See figures in supporting). The reactivity of complexes $\mathbf{2}$ and $\mathbf{3}$ with $\mathrm{CS}_{2}$ is in agreement with a nucleophilic character of the nitride. Notably, the addition of ${ }^{13} \mathrm{CS}_{2}$ at $-40{ }^{\circ} \mathrm{C}$ in THF to the 
bridging nitride leads to the isolation of the disulfide bridged diuranium(IV) complex $(\mathrm{Cs}(\mathrm{THF}))_{2}\left[\left\{\mathrm{U}\left(\mathrm{OSi}\left(\mathrm{O}^{\mathrm{t} B u}\right)_{3}\right)_{3}\right\}_{2}(\mu-\mathrm{S})_{2}\right], 4$ in $25 \%$ yield that was characterized by X-ray diffraction studies (see supporting information). ${ }^{13} \mathrm{C}$ NMR of the reaction mixture allowed identification of the product of nitride transfer to $\mathrm{CS}_{2}$ as the thiocyanate $\mathrm{SCN}^{-}$species. The disulfide complex is thus likely to be formed by extrusion of CsSCN from a highly reactive dithiocarbamate intermediate. Proton NMR studies show that the formation of 4 occurs immediately even at low temperature and it was not possible to isolate any intermediate. Similar reactivity has been reported for a terminal $V(V)$ nitride, but in that case decomposition is slower and the dithiocarbamate intermediate was isolated. ${ }^{[12]}$ However, the formation of 4 involves the oxidation of the metal center from U(III) to U(IV) and therefore additional products must be formed that remain unidentified.

In conclusion, here we have expanded the family of molecular uranium nitride complexes to the +III oxidation state. This has been accomplished by reducing the U(IV) analogue with cesium metal. Structural studies point to the presence of UIII-N multiple bonding. Future studies will be directed to further investigate the nature of U-N bonding in these systems. The reported reactivity with $\mathrm{CS}_{2}$ is in agreement with a nucleophilic character of the nitride group. These complexes associating the highly reducing uranium (III) to a multiply-bonded nitride group provide unprecedented precursors for the discovery of novel reactivity and unusual transformations. We are currently investigating the reactivity of these complexes with various substrates.

\section{ASSOCIATED CONTENT}

Supporting Information. Experimental procedures, spectral data, (PDF file), and crystallographic information (CIF files).

The Supporting Information is available free of charge on the ACS Publications website.

\section{AUTHOR INFORMATION}

\section{Corresponding Author}

marinella.mazzanti@epfl.ch

\section{Funding Sources}

This work was supported by the Swiss National Science Foundation and by the Ecole Polytechnique Fédérale de Lausanne (EPFL). No competing financial interests have been declared.

\section{ACKNOWLEDGMENT}

We thank Euro Solari for carrying out the elemental analyses and for technical support. We thank Marta Falcone for some preliminary experiments.

\section{REFERENCES}

[1] D. M. King, S. T. Liddle, Coord. Chem. Rev. 2014, 266, 2-15.

[2] (a) G. W. C. Silva, C. B. Yeamans, A. P. Sattelberger, T. Hartmann, G. S. Cerefice, K. R. Czerwinski, Inorg. Chem. 2009, 48, 10635-10642; (b) L. Black, F. Miserque, T. Gouder, L. Havela, J. Rebizant, F. Wastin, J. Alloys Compd. 2001, 315, 36-41; (c) D. W. Green, G. T. Reedy, J. Chem. Phys. 1976, 65, 2921-2922; (d) L. Andrews, X. F. Wang, Y. Gong, G. P. Kushto, J. Phys. Chem. A 2014, 118, 5289-5303.

[3] M. Streit, F. Ingold, J. Eur. Ceram. Soc. 2005, 25, 2687 2692.

[4] (a) F. Haber, Vol. DE 229126, Haber, F Ammonia German patent DE 229126, 1909; (b) A. R. Fox, S. C. Bart, K. Meyer, C. C. Cummins, Nature 2008, 455, 341-349.

[5] (a) M. L. Neidig, D. L. Clark, R. L. Martin, Coord. Chem. Rev. 2013, 257, 394-406; (b) N. Kaltsoyannis, Inorg. Chem. 2013, 52, 3407-3413; (c) T. W. Hayton, Chem. Commun. 2013, 49, 2956-2973.

[6] (a) W. J. Evans, S. A. Kozimor, J. W. Ziller, Science 2005, 309, 1835-1838; (b) I. Korobkov, S. Gambarotta, G. P. A. Yap, Angew. Chem. Int. Ed. Engl. 2002, 41, 3433-3436; (c) T. K. Todorova, L. Gagliardi, J. R. Walensky, K. A. Miller, W. J. Evans, J. Am. Chem. Soc. 2010, 132, 12397-12403; (d) G. Nocton, J. Pecaut, M. Mazzanti, Angew. Chem. Int. Ed. Engl. 2008, 47, 3040-3042; (e) S. Fortier, G. Wu, T. W. Hayton, J. Am. Chem. Soc. 2010, 132, 6888-6889; (f) A. R. Fox, P. L. Arnold, C. C. Cummins, J. Am. Chem. Soc. 2010, 132, 3250-3251; (g) C. Camp, J. Pecaut, M. Mazzanti, J. Am. Chem. Soc. 2013, 135, 12101-12111; (h) L. Maria, I. C. Santos, V. R. Sousa, J. Marcalo, Inorg. Chem. 2015, 54, 9115-9126.

[7] (a) R. K. Thomson, T. Cantat, B. L. Scott, D. E. Morris, E. R. Batista, J. L. Kiplinger, Nat. Chem. 2010, 2, 723-729; (b) D. M. King, F. Tuna, E. J. L. McInnes, J. McMaster, W. Lewis, A. J. Blake, S. T. Liddle, Nat. Chem. 2013, 15, 482-488; (c) D. M. King, F. Tuna, E. J. L. McInnes, J. McMaster, W. Lewis, A. J. Blake, S. T. Liddle, Science 2012, 337, 717-720; (d) D. M. King, J. McMaster, F. Tuna, E. J. L. McInnes, W. Lewis, A. J. Blake, S. T. Liddle, J. Am. Chem. Soc. 2014, 136, 5619-5622.

[8] P. A. Cleaves, D. M. King, C. E. Kefalidis, L. Maron, F. Tuna, E. J. L. McInnes, J. McMaster, W. Lewis, A. J. Blake, S. T. Liddle, Angew. Chem. Int. Ed. Engl. 2014, 53, 10412-10415.

[9] (a) G. Cloke, F. N., P. B. Hitchcock, J. Am. Chem. Soc. 2002, 124, 9352-9353; (b) P. Roussel, P. Scott, J. Am. Chem. Soc. 1998, 120 , 1070-1071.

[10] J. L. Stewart, R. A. Andersen, Polyhedron 1998, 17, $953-$ 958.

[11] J. M. Smith, Prog. Inorg. Chem. 2014, 58, 417-470.

[12] J. K. Brask, V. Dura-Vila, P. L. Diaconescu, C. C. Cummins, Chem. Commun. 2002, 902-903. 
SYNOPSIS TOC

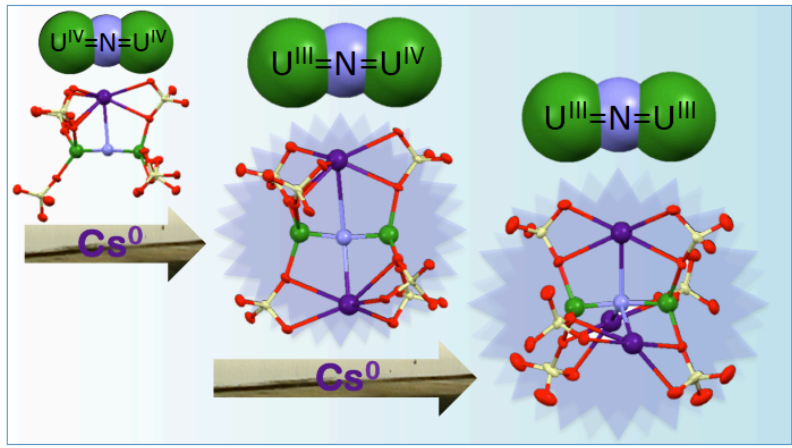

